\title{
Um Estudo Sociofuncional sobre a Variação/Estratificação entre Você e Cê em uma Comunidade do Sertão da Ressaca: O Teste de Avaliação em Foco
}

\author{
A Sociofunctional Study on the Variation/Layering between Você and Cê in a \\ Community from Sertão da Ressaca: The Evaluation Test in Focus
}

\author{
Warley José Campos Rocha* \\ Universidade Estadual do Sudoeste da Babia \\ Vitória da Conquista - Bahia, Brasil. \\ Valéria Viana Sousa** \\ Universidade Estadual do Sudoeste da Babia \\ Vitória da Conquista - Bahia, Brasil.
}

\begin{abstract}
Resumo: Neste artigo, temos como principal objetivo apresentar os resultados e discussões decorrentes de um teste de avaliação, o qual compôs uma parte do estudo que buscou descrever a variação/estratificação entre os pronomes você e cê, em posição pré-verbal, na função de sujeito de orações finitas, presente na comunidade de fala de Vitória da Conquista - BA (ROCHA, 2017). Quanto ao aporte teórico-metodológico, baseamo-nos no Sociofuncionalismo (LABOV, 2008 [1972]; HOPPER, 1991; TAVARES, 2003), o que permitiu discutir os dados e apresentar as conclusões alcançadas no estudo empreendido a partir da aplicação do referido teste, uma vez que, ao final das análises dos grupos de fatores linguísticos e sociais, foram observados indícios de estigma no que diz respeito ao uso da variante cê. Diante disso, perguntamo-nos se o uso preferencial pela forma conservadora, você, seria motivado pelos valores sociais das variantes e, assim, aplicamos um teste de atitude com dezessete informantes escolarizados da comunidade de fala em foco. Feito isso, foi possível comprovar que não há a presença de estereótipos referentes ao uso do cê no vernáculo conquistense.
\end{abstract}

Palavras-chave: Alternância pronominal. Teste de avaliação. Sociofuncionalismo. Estigmatização.

Abstract: In this article, we have as main objective to present the results and discussions resulting from an evaluation test, which composed a part of the study that sought to describe the variation/layering between the pronouns você and $c \hat{e}$, in a pre-verbal position, in the subject function of finite sentences, present in the speech community of Vitória da Conquista - BA (ROCHA, 2017). As for the theoretical-methodological contribution, we based on Sociofunctionalism (LABOV, 2008 [1972]; HOPPER, 1991; TAVARES, 2003), which allowed us to discuss the data and present the conclusions reached in the study undertaken from the application of that test, since, at the end of the analyzes of the groups of linguistic and social factors, signs of stigma were observed with regard to the use of the variant cê. Therefore, we wondered if the preferential use for the conservative form, você, would be motivated by the social values of the variants and, thus, we applied an evaluation test with seventeen schooled informants from the focused speech community. That done, it was possible to prove that there is no presence of stereotypes regarding the use of $c \hat{e}$ in the vernacular of Conquista.

Keywords: Pronominal alternation. Evaluation test. Sociofunctionalism. Stigmatization.

\section{INTRODUÇÃO}

\footnotetext{
* Doutorando em Linguística pela Universidade Estadual do Sudoeste da Babia (UESB/PPGLin), Vitória da Conquista - Bahia, Brasil. E-mail: warleycampos@live.com.

** Doutora em Letras/Linguística e Língua Portuguesa pela Universidade Federal da Paraíba (UFPB). Professora Titular da Universidade Estadual do Sudoeste da Babia (UESB/PPGLin), Vitória da Conquista Bahia, Brasil. E-mail: valeriavianasousa@gmail.com.
} 
As formas pronominais protagonizam muitos estudos linguísticos que intentam investigar vernáculos específicos encontrados em toda a extensão do Brasil, os quais, por seu turno, constituem uma variedade linguística maior, que é o Português Brasileiro. Ampliando esse cenário científico, apresentamos, neste artigo, uma parte do estudo desenvolvido por Rocha (2017), no âmbito da investigação pronominal, cujos pressupostos teórico-metodológicos ancoram-se no Sociofuncionalismo, objetivando descrever a variação/estratificação entre os pronomes você e cê, em posição pré-verbal, na função de sujeito de orações finitas, presente na comunidade de fala de Vitória da Conquista - BA. É importante ressaltar que o estudo do vernáculo de uma comunidade implica não apenas realizar a descrição e a análise linguística de um fenômeno, mas, também, cabe, por vezes, para uma melhor compreensão, propor uma reflexão e explicitar as atitudes avaliativas da comunidade a respeito do fenômeno linguístico em estudo.

A pesquisa foi realizada em um eixo pancrônico, uma vez que, inicialmente, foi trabalhada a sócio-história do objeto e, posteriormente, verticalizou-se o olhar em uma amostra sincrônica do vernáculo conquistense. Feitas as análises da alternância entre o pronome você e sua forma variante cê a partir de grupos de fatores previamente definidos, foram observados indícios de estigma sofrido pela forma sincopada cê. Todavia, os dados linguísticos e sociais ora analisados não subsidiavam ainda uma conclusão concreta, que refutaria, assim, tais indícios e confirmaria a hipótese de que a forma inovadora estava em franca expansão de uso na referida comunidade de fala, sem sofrer, portanto, qualquer estigmatização.

Por essa razão, verificamos a necessidade de se aplicar um teste de avaliação, com vistas a demonstrar que os informantes de Vitória da Conquista, sobretudo, os mais escolarizados, não apresentavam resistência ou juízo de valor negativo quan to ao emprego da forma inovadora cê. Desse modo, baseando-nos nessa alternativa metodológica, objetivamos, com o presente artigo, dar destaque aos resultados encontrados nesta segunda etapa de análises e comprovar que a variação/estratificação entre as formas pronominais em foco exemplificam uma das categorias teorizadas por Labov (2008 [1972]) no que tange ao valor social das variantes, neste caso, os marcadores.

O texto é organizado, além da Introdução, em outras cinco seções, a saber: Referencial Teórico, em que apresentamos, em linhas gerais, a teoria que deu suporte à pesquisa, bem como considerações acerca da parte inicial do estudo de Rocha (2017); Metodologia, na qual descrevemos o locus da pesquisa e exibimos os procedimentos relacionados à realização do teste de avaliação; $O$ teste de avaliação e suas análises, em que destacamos as perguntas do teste de avaliação e sublinhamos as ponderações do autor da pesquisa face às respostas dadas pelos participantes do teste; Conclusão, seção destinada às últimas ponderações a serem feitas sobre o estudo em foco, seguidas das Referências.

\section{REFERENCIAL TEÓRICO}

$\mathrm{Na}$ presente seção, conforme anunciado na Introdução, destacamos tanto os pressupostos teórico-metodológicos que ampararam a pesquisa aqui focalizada, por meio da subseção Sociofuncionalismo, quanto os resultados e análises que antecederam e 
motivaram a etapa da pesquisa focalizada neste artigo, a partir da subseção Você e cê no Sertão da Ressaca: ponderações preliminares. Passemos, então, para as referidas subseções.

\subsection{SOCIOFUNCIONALISMO}

Em um estudo sociofuncional, analisamos os resultados da pesquisa pelo crivo da conciliação entre a Sociolinguistica Variacionista (cf. WEINREICH; LABOV; HERZOG, 2008 [1968]; LABOV, 2008 [1972]; GUY; ZILLES, 2007; TARALLO, 2007, entre outros) e o Funcionalismo Norte-Americano voltado à gramaticalização (cf. HOPPER, 1987; HOPPER, 1991, HEINE; CLAUDI; HUNNEMEYER, 1991; GIVÓN, 1995; HEINE, 2003; HOPPER; TRAUGOTT, 2003; entre outros). Compreendemos, a partir dos pressupostos teóricos utilizados, que o estudo pauta-se, então, no Sociofuncionalismo (TAVARES, 2003; TAVARES, 2013; TAVARES; GÖRSKI, 2015).

Tavares e Görski (2015) advogam que há benefícios nessa incorporação de assumpções funcionalistas no momento de se fazer uma análise de natureza variacionista. Segundo as pesquisadoras, entre outras coisas, observa-se um controle mais acurado dos grupos de variáveis linguísticas, visto que se pode restringir o contexto discursivo e pragmático via tratamento de análise escalar. Outrossim, é possível tornar fenômenos reconhecidamente funcionais em variáveis, além de o aspecto social da variação ser, ainda, considerado com mais detalhe nesse modo de se conceber a análise. Tavares (2003) salienta, também, que existe a possibilidade de se assumir o Sociofuncionalismo em uma perspectiva plural. Em outras palavras, podemos falar de um Sociofuncionalismo mais variacionista ou um Sociofuncionalismo mais funcionalista.

Nesse diapasão, tendo em vista a pesquisa que ora apresentamos neste artigo, ressaltamos que a abordagem feita aqui se alinha ao modelo sociofuncionalista mais voltado à Sociolinguística Variacionista, na medida em que colocamos em destaque um dos instrumentos de análise, com frequência, utilizado pelos sociolinguistas, a saber, o teste de avaliação. Entretanto, cabe a ressalva de que não descartamos a compreensão funcionalista da gramática enquanto emergente e em constante processo de construção. E, a nosso ver, a despeito da predicação ser inerente a cada uma das correntes teóricas, o conceito de regra variável relaciona-se diretamente com a ideia de estruturas maleáveis, afinal, ambas percebem a variabilidade ordenada da língua.

Com o teste de avaliação mencionado anteriormente, podemos ter uma noção, ou melhor, percepção, do que, no seio da teoria laboviana, é chamado de valor ou significado social das variantes. Isso diz respeito às questões relacionadas ao prestígio e/ou estigma, os quais são observadas a partir da reação/relação de falantes de uma determinada comunidade de fala face ao uso de uma dada variante linguística. Nessa direção, Labov (2008 [1972], p.362) argumenta que "O estigma social conferido a alguns [...] estereótipos tem levado à mudança linguística rápida, com extinção quase total”, o que nos leva a compreender que o valor atribuído por uma comunidade a determinada variante pode contribuir para refrear ou acelerar uma mudança na língua.

Nesse cenário da teoria, a partir dos julgamentos sociais a respeito da língua, os quais se dão consciente ou inconscientemente, encontram-se os conceitos de estereótipos, marcadores e indicadores. Levando em consideração o que preconiza Labov (2008 [1972], 
p.360), os estereótipos consistem em traços linguísticos marcados socialmente, considerando, para tanto, total consciência dos falantes. Em suas palavras, são caracterizados como formas "[...] rotuladas enfaticamente pela sociedade. [...]" Os marcadores, por sua vez, são traços linguísticos presentes na esfera social e estilística, os quais podem ser identificados por meio de determinados testes de avaliação, embora o julgamento por parte ouvinte possa estar abaixo do seu nível de consciência. Os indicadores, por seu turno, “[...] traços linguísticos encaixados numa matriz social, exibindo diferenciação segundo a idade e o grupo social [...]", são entendidos como variáveis dialetais que podem diferenciar categorias sociais ou geográficas, mas sem que haja variação no continuum de formalidade ou estilístico e sem expressar grande avaliação.

Feitas tais considerações, prossigamos para a próxima subseção, em que apresentamos, de forma sintética, o estudo de Rocha (2017) e algumas conclusões provenientes dos dados estatísticos encontrados na pesquisa realizada.

\subsection{VOCÊE E CÊ NO SERTÃO DA RESSACA: PONDERAÇÕES PRELIMINARES}

Neste artigo, focalizamos uma parte importante do estudo de Rocha (2017), dando um destaque aos resultados e conclusões decorrentes da aplicação do teste de avaliação, o qual teve por finalidade o refinamento das análises da variação/estratificação entre os pronomes você e cê, em posição pré-verbal, na função de sujeito de orações finitas, em Vitória da Conquista - BA. Todavia, antes de apresentarmos as principais ponderações sobre o referido teste na seção $O$ teste de avaliação e suas análises, ressaltamos a relevância de exibirmos, nesta subseção, os delineamentos metodológicos da parte que antecedeu a execução do teste e as conclusões provenientes dos resultados estatísticos, os quais, inclusive, apontaram para um dado indício de estigma no tocante à variante $c \hat{e}$.

No referido trabalho, descrevemos o objeto de estudo a priori à luz da Sóciohistória, por meio de gramáticas históricas, na sequência, observando-o nas gramáticas prescritivas e descritivas, além de registrar um número considerável de estudos linguísticos no Brasil dentro da temática. O estudo é ancorado no Sociofuncionalismo, teoria cuja apresentação foi feita na subseção anterior. Com relação à metodologia, no intuito de analisar a alternância entre o você e o cê, foram determinados grupos de fatores, sendo eles: (i) natureza semântico-funcional; (ii) paralelismo formal; (iii) superestrutura textual; (iv) faixa etária; (v) sexo; e (vi) escolaridade.

Para a análise, investigamos vinte e quatro entrevistas, as quais foram extraídas de dois corpora orais, o Corpus do Português Popular de Vitória da Conquista (Corpus PPVC) e o Corpus do Português Culto de Vitória da Conquista (Corpus PCVC) ${ }^{1}$. A seleção das entrevistas deu-se a partir de três faixas etárias, a saber: (a) faixa I - de 15 a 35 anos; (b) faixa II - de 36 anos a 49 anos; (c) faixa III - de 50 anos em diante, além de seguir as

\footnotetext{
1 Objetivando descrever a variedade do Português Brasileiro (culto e popular) falada na cidade de Vitória da Conquista - BA, os pesquisadores do Grupo de Pesquisa em Linguística Histórica e em Sociofuncionalismo - CNPq empreenderam, entre os anos de 2011 e 2015, o projeto de construção do Corpus PCVC, com falantes com 11 (onze) anos ou mais de escolaridade; e Corpus PPVC, em que os entrevistados detinham até 4 (quatro) anos de escolaridade.
} 
seguintes especificações: doze entrevistas de informantes do sexo masculino e outras doze de informantes do sexo feminino.

Foi coletado um total de 788 (setecentos e oitenta e oito) dados, considerando que $56 \%$ das ocorrências representaram o uso do pronome você e $44 \%$ delas corresponderam ao emprego da forma variante cê. Após terem sido feitas as análises estatísticas para todos os grupos de fatores, bem como os cruzamentos necessários, concluímos que houve claros indícios de que, em Vitória da Conquista - BA, a variação entre os pronomes você e cê encontra-se em mudança em curso em direções divergentes, na medida em que se for levada em consideração a fala dos informantes mais jovens do Português Popular, a variante cê está em franca expansão de uso, ao passo que o comportamento linguístico dos informantes do Português Culto das primeiras faixas etárias revela uma atitude linguística mais conservadora, já que é o pronome você a variante favorecida nesse caso.

Além das considerações feitas, é relevante tratarmos das conclusões relacionadas às variáveis sociais controladas no estudo, a saber: faixa etária, sexo e escolaridade. Percebemos o quanto as marcas subjetivas da sociedade influenciam no curso da língua, na medida em que, na comunidade de Vitória da Conquista - BA, enquanto os jovens mais escolarizados favorecem o uso do pronome você, os informantes mais escolarizados da faixa III favorecem a forma inovadora cê, ao passo que os informantes menos escolarizados favorecem as camadas/variantes exatamente de modo contrário. As mulheres e homens mais escolarizados da amostra investigada também favorecem o uso da forma conservadora, ao contrário das mulheres e homens menos escolarizados que lideram com o favorecimento da forma inovadora.

A partir das ponderações feitas sobre os grupos de fatores sociais, observamos claramente a relevância da aplicação do teste de avaliação, pois, estatisticamente, os dados demonstram oposições de prestígio social no tocante ao emprego das variantes em estudo. Rocha (2017) defende categoricamente que não há estigma no que diz respeito ao emprego da forma pronominal cê. Para amparar seu posicionamento, o pesquisador afirma, entre outras coisas, que se vale de: análises linguísticas, como, por exemplo, a expansão do uso inovador da referência indefinida na língua; o fato dos informantes mais escolarizados da faixa III favorecerem a forma sincopada $c \hat{e}$; a estreita relação entre a região norte de Minas Gerais e a comunidade de fala em estudo; e subsídios provenientes do próprio teste de avaliação aplicado pelo pesquisador.

Assim, fechamos esta seção, dando continuidade às demais discussões com as considerações atinentes à metodologia, mais especificamente, aos procedimentos metodológicos relacionados à aplicação do teste de avaliação, foco do presente artigo.

\section{METODOLOGIA}

Na subseção Você e Cê no Sertão da Ressaca: Ponderações Preliminares, antecipamo-nos e apresentamos a composição e organização dos corpora investigados, todavia, como temos o como principal objetivo apresentar a parte do estudo voltado à aplicação do teste de avaliação, nesta seção, apresentamos duas subseções em que trataremos do locus da pesquisa e dos delineamentos relacionados ao referido teste. Passemos a elas. 


\subsection{LOCUS DA PESQUISA}

A comunidade de fala selecionada para o desenvolvimento da pesquisa, no caso, a de Vitória da Conquista - Bahia, encontra-se no Sertão da Ressaca, região brasileira que é conhecida no cenário nacional por, entre outros motivos: ser o berço ou o lugar onde se instalaram ícones da música, da literatura, da escultura, da pintura e do cinema, tais como Elomar Figueira, José Mozart Tanajura, Aurino Cajaíba da Silva, Sílvio Jessé, Glauber Rocha; por ser um dos grandes centros de criação de gado, produção e exportação de café e de outras culturas; além de ser um lugar que abastece outras regiões da Bahia e do norte de Minas Gerais, que se encontram em seu entorno, com serviços voltados à educação, saúde e geração de empregos.

Sobre a delimitação do Sertão da Ressaca ${ }^{2}$, a região encontra-se nos limites entre os rios Pardo e das Contas, abarcando um território na Mesorregião Centro-Sul da Bahia, a qual se constitui de numerosos centros urbanos, com proporções maiores ou menores, rodeados por perímetros rurais. Vitória da Conquista - BA, o centro urbano selecionado para realização do estudo, localiza-se em um ponto central do Sertão da Ressaca, sendo reconhecida por alguns como a capital da referida região.

De acordo com informações obtidas pelo Instituto Brasileiro de Geografia e Estatística (IBGE), Vitória da Conquista possuía, no ano de 2016, uma população composta por cerca de 346.069 (trezentos e quarenta e seis mil e sessenta e nove) habitantes. É, consensualmente, a terceira maior cidade do Estado da Bahia, correspondendo a uma área total de 3.204.257 (três milhões duzentos e quatro mil duzentos e cinquenta e sete) $\mathrm{km}^{2}$.

Não podemos deixar de destacar, também, a relação entre Vitória da Conquista e o Norte de Minas Gerais. A respeito disso:

[...]além das cidades baianas que são abastecidas por Vitória da Conquista - BA, não podemos negar a estreita relação desta com as cidades e as pequenas comunidades do norte do Estado de Minas Gerais. As conexões entre o norte mineiro e os sertões baianos, onde se encontra Vitória da Conquista - BA, dão-se há muito tempo. Ivo (2012, p.115), por sua vez, argumenta que "[...] o norte de Minas Gerais estava conectado com os sertões da Bahia desde os primeiros anos da colonização e, a partir do século XVIII, estes contatos foram intensificados com as buscas de riquezas minerais [...]". (ROCHA, 2017, 158).

\footnotetext{
2 “[...] Os portugueses utilizaram termos do mar ou da costa tanto para acidentes geográficos como também para a vida sertaneja. Navegar pelo sertão, por exemplo, ou baía de mato, baía (lagoa formada pelos rios ao longo de suas margens); ou galeota (para denominar pequeno carro manual de transporte de mercadoria em feira); enseada (área de campo entre dois igarapés, área de campo numa volta do rio); praia (leito de riacho coberto de cascalho) etc. O relevo formado por vales semicirculares assemelhados, em sua forma, ao recuo das águas da praia para o mar. Talvez essa seja a origem do termo: o emprego, mais uma vez, de vocábulo aplicável ao movimento das ondas, ao movimento do relevo no interior." (MEDEIROS, 2013, p.43 apud ROCHA, 2017, p. 96) (grifos do autor)
} 
Notamos, dessa forma, que a estreita relação entre as referidas regiões se dá, há um tempo considerável, visto que, desde a colonização, já havia o trânsito, entre elas, de pessoas com interesses bem definidos, intensificando-se até a contemporaneidade. Assim, apresentado o locus do estudo, avancemos para a próxima subseção.

\subsection{TESTE DE AVALIAÇÃO}

Tratando-se do mapeamento dos respondentes do teste de avaliação, foi recrutado um número de informantes mais escolarizados, presentes na amostra delineada na subseção 2.2 e outros informantes de Vitória da Conquista que possuíssem mais de onze anos de escolaridade, para participar dessa etapa da pesquisa. É válido sublinhar que o principal objetivo de se aplicar o teste foi provar que não existe estigma no que diz respeito ao uso da variante cê na comunidade em foco.

Vejamos:

O teste foi constituído por cinco questões, as quais são apresentadas no Quadro 1.

Quadro 1 - Relação de questões do teste de avaliação ${ }^{3}$

\begin{tabular}{|l|}
\hline \multicolumn{1}{|c|}{ QUESTÕES } \\
\hline 1 - Nesse primeiro momento, gostaríamos de saber a sua opinião sobre a forma \\
como os conquistenses falam. Você percebe alguma característica no modo de \\
falar dos conquistenses que os identifica ou diferencia da maneira de falar de \\
pessoas de outro(s) lugar(es)? Ou alguma semelhança como a maneira de falar de \\
outros lugares? \\
\hline 2 - Dentre as sentenças abaixo, há alguma que você NÃO diria? \\
( ) 1 - Você pode me encontrar amanhã. \\
( ) 2 - Cê passa lá em casa. \\
( ) 3 - Você estuda onde? \\
( ) 4 - Eu trouxe isso pra você. \\
( ) 5 - Ele não gosta de cê. \\
( ) 6 - Cê tá onde? \\
( ) 7 - Você pode pegar o ônibus UESB. \\
( ) 8 - Cê compra isso na farmácia. \\
Se você marcou alguma das alternativas acima, o que lhe levou a assinalá-la? \\
\hline 3 - Estudos comprovam que os conquistenses usam tanto o pronome $V O C E$ \\
quanto o pronome $C \hat{E}$. Você também usa os dois pronomes? Por favor, apresente \\
uma breve justificativa. \\
\hline 4 - O que você acha do uso do pronome $C \hat{E}$ ? \\
\hline 5 - Você usa o pronome TU? Em que situações você usa (ou prefere usar) o tu \\
em detrimento ao $V O C E \hat{E} / C E \hat{?}$ ?
\end{tabular}

Fonte: Elaboração própria

${ }^{3}$ Para elaboração do Quadro 1, contamos como as informações apresentadas no Apêndice A da dissertação de Rocha (2017). 
Uma vez apresentadas as perguntas do teste de avaliação, é importante também destacarmos o mapeamento dos informantes que participaram do teste. Ressaltamos que, na próxima seção, lançaremos mão das siglas dos nomes dos informantes, presentes no Quadro 2, para discutirmos as respostas dadas. Vejamos, portanto, como se configurou a amostra do estudo relacionada ao teste de avaliação.

Quadro 2 - Mapeamento dos informantes conquistenses que responderam o teste de avaliação/percepção

\begin{tabular}{|c|c|c|}
\hline \multicolumn{2}{|c|}{ DISTRIBUIÇÃO DOS INFORMANTES DO TESTE DE AVALIAÇÃO } \\
\hline INFORMANTE & SEXO & FAIXA ETÁRIA \\
\hline D.T.B. & MASCULINO & FAIXA I \\
\hline F.S.L.B. & MASCULINO & FAIXA I \\
\hline I.U.S.S. & MASCULINO & FAIXA I \\
\hline T.M.L.C. & MASCULINO & FAIXA I \\
\hline Y.C. & MASCULINO & FAIXA I \\
\hline C.B.S. & FEMININO & FAIXA I \\
\hline G.G.J. & FEMININO & FAIXA I \\
\hline M.T.R. & FEMININO & FAIXA I \\
\hline V.M.S.N. & FEMININO & FAIXA I \\
\hline A.L.P. & MASCULINO & FAIXA II \\
\hline K.R.L.A. & FEMININO & FAIXA II \\
\hline L.S.S. & FEMININO & FAIXA II \\
\hline N.L.A. & FEMININO & FAIXA II \\
\hline A.C. & MASCULINO & FAIXA III \\
\hline P.A.R.C. & MASCULINO & FAIXA III \\
\hline E.G.S. & MASCULINO & FAIXA III \\
\hline A.I.R.M & FEMININO & FAIXA III \\
\hline
\end{tabular}

Fonte: Rocha (2017, p. 113)

A partir do Quadro 2, observamos que a maior parte dos informantes encontra-se na faixa I. Isso se justifica em função da ausência de um dado equilíbrio em relação à quantidade de informantes entre as faixas etárias, baseando-se no objetivo de se verificar, especialmente, entre os informantes jovens mais escolarizados, suas percepções linguísticas, no que diz respeito ao emprego da variante $c \hat{e}$, pois, observamos, por meio das estatísticas, um comportamento conservador exatamente no referido recorte etário.

Postas todas essas especificidades metodológicas, sigamos, então, para as discussões decorrentes das respostas dos informantes.

\section{O TESTE DE AVALIAÇÃO E SUAS ANÁLISES}

Diante dos resultados obtidos, bem como das análises possíveis de serem feitas por meio deles, constatamos a necessidade de se realizar um teste de avaliação para confirmarmos a hipótese de que a forma sincopada cê não sofre estigma na comunidade de Vitória da Conquista - BA. Dessa forma, além de compreendermos que, em nosso 
objeto, atuam forças estruturais, não pudemos deixar de nos atentar também às influências externas ao sistema linguístico, o que tanto explicaria o comportamento conservador das faixas mais jovens quanto confirmaria a nossa hipótese.

Prossigamos, então, para as respostas dadas pelos informantes e as possíveis considerações decorrentes delas. No Quadro 3, estão apresentadas as respostas dadas para a primeira questão. Vejamos:

Quadro 3 - As respostas do teste de avaliação para a primeira pergunta sobre o dialeto conquistense

\begin{tabular}{|c|c|}
\hline \multicolumn{2}{|c|}{$\begin{array}{l}\text { PERGUNTA: Nesse primeiro momento, gostaríamos de saber a sua opinião sobre a } \\
\text { forma como os conquistenses falam? Você percebe alguma característica no modo de } \\
\text { falar dos conquistenses que os identifica ou diferencia da maneira de falar de pessoas } \\
\text { de outro(s) lugar(es)? Ou alguma semelhança como a maneira de falar de outros } \\
\text { lugares? }\end{array}$} \\
\hline INFORMANTES & RESPOSTAS \\
\hline D.T.B. & "Não identifico qualquer traço distintivo na fala do conquistense." \\
\hline F.S.L.B. & $\begin{array}{l}\text { "A fala dos conquistenses se diferencia da fala de outros lugares, como } \\
\text { por exemplo o extremo nordeste do país onde se pronuncia oclusivas } \\
\text { alveolares, não as africadas correspondentes que os conquistenses } \\
\text { produzem. Também a prosódia conquistense é diferente daquela usada } \\
\text { no extremo nordeste, bem como a de outras regiões do país, como sul } \\
\text { e sudeste. A fala conquistense se assemelha, parcialmente, à fala paulista } \\
\text { no que se refere às consoantes e vogais." }\end{array}$ \\
\hline I.U.S.S. & $\begin{array}{l}\text { "Não consigo perceber de maneira impactante, uma característica em } \\
\text { específico, que diferencie a nossa fala em detrimento a de outros locais. } \\
\text { Porém, quando em contato com pessoas de locais diferentes, como a } \\
\text { nossa própria capital, é gritante nossa diferença na maneira de falar." }\end{array}$ \\
\hline T.M.L.C. & $\begin{array}{l}\text { "Acredito que os conquistenses, assim como os indivíduos que vivem } \\
\text { na região sudoeste da Bahia, diferem muito dos demais habitantes do } \\
\text { estado no que diz respeito ao sotaque expressões que usualmente são } \\
\text { utilizadas, de modo que, frequentemente, aproximam-se muito dos } \\
\text { mineiros. De maneira geral, os habitantes de Vitória da Conquista } \\
\text { compartilham poucas características na maneira de falar com os } \\
\text { soteropolitanos, por exemplo." }\end{array}$ \\
\hline Y.C. & $\begin{array}{l}\text { "Nós conquistenses, achamos que não temos sotaque, entretanto } \\
\text { temos, e puxamos para o mineiro." }\end{array}$ \\
\hline C.B.S. & $\begin{array}{l}\text { "Creio que nós conquistenses temos uma mistura de dois sotaques: o } \\
\text { baiano e o mineiro. Visto que, utilizamos expressões em nosso } \\
\text { cotidiano fortemente empregadas na Bahia, assim como, reduzimos } \\
\text { muitas palavras na hora da fala, como fazem os mineiros. Creio que } \\
\text { isso destoa o nosso sotaque do restante do estado, que tendem para } \\
\text { algo mais próximo dos soteropolitanos ou aquele que se assemelha a } \\
\text { outros estados do Nordeste." }\end{array}$ \\
\hline G.G.J. & "Acho muito semelhante a maneira de falar dos mineiros." \\
\hline M.T.R. & $\begin{array}{l}\text { "Uma característica bem marcante no modo de falar dos conquistenses } \\
\text { é a mistura do 'baianês' com o 'mineirês'. A proximidade da cidade com } \\
\text { o norte de Minas Gerais e a distância em relação à Salvador faz com }\end{array}$ \\
\hline
\end{tabular}




\begin{tabular}{|c|c|}
\hline & $\begin{array}{l}\text { que os conquistenses falem de forma bem mais parecida com o jeito de } \\
\text { falar dos mineiros." }\end{array}$ \\
\hline V.M.S.N. & $\begin{array}{l}\text { "Acredito que por conta da localização geográfica, os habitantes de } \\
\text { Vitória da Conquista sofrem muita influência do norte de Minas Gerais } \\
\text { no que diz respeito ao modo de falar. Tendo sotaque, gírias e demais } \\
\text { hábitos de fala, mais parecidos com os dos mineiros do que dos } \\
\text { soteropolitanos e dos habitantes do norte do estado, por exemplo." }\end{array}$ \\
\hline A.L.P. & $\begin{array}{l}\text { "Apesar de estarmos no nordeste, acho que somos muitos mais } \\
\text { influenciados na linguagem pelo sudeste, especificamente por Minas } \\
\text { Gerais, principalmente a utilização do "moço" ou "moss" em diversas } \\
\text { situações. Nosso sotaque é muito divergente de outras regiões do } \\
\text { estado, principalmente da região metropolitana de Salvador e do norte, } \\
\text { talvez pelo uso de gírias serem menos utilizadas aqui em relação as } \\
\text { regiões citadas. Acho a sonoridade, o tom de voz utilizado aqui mais } \\
\text { suave. Um exemplo seria o T, aqui não falamos de forma cantada como } \\
\text { ocorre no norte do estado e na maioria dos estados nordestinos." }\end{array}$ \\
\hline K.R.L.A. & $\begin{array}{l}\text { "Percebo diferença em relação a outras regiões da Bahia e percebo } \\
\text { também, influência do sotaque e expressões mineiras." }\end{array}$ \\
\hline L.S.S. & $\begin{array}{l}\text { "Os conquistenses carregam o peso sim do baianês mas traz um pouco } \\
\text { do cantar mineiro prefiro dizer que temos um falar próprio com nossas } \\
\text { individualidades, mas não muito distantes de um baimineirês." }\end{array}$ \\
\hline N.L.A. & $\begin{array}{l}\text { "Percebo uma mistura de falas entre os conquistenses, acredito que } \\
\text { devido à proximidade com a capital e também com estado de minas." }\end{array}$ \\
\hline A.C. & $\begin{array}{l}\text { "Sim , inclusive quanto ao sotaque. Lembra a forma de falar do Norte } \\
\text { de Minas Gerais." }\end{array}$ \\
\hline P.A.R.C. & $\begin{array}{l}\text { "Percebo o uso de expressões e formas de entonação e pronúncia que } \\
\text { são próprias dos conquistenses, mas que podem ser verificadas também } \\
\text { em algumas cidades que estão sob a sua área de influência geográfica, } \\
\text { política, econômica e cultural." }\end{array}$ \\
\hline E.G.S. & $\begin{array}{l}\text { "Essa questão é complexa. Veja bem, temos inclusive um artista } \\
\text { conquistense, Elomar Figueira de Melo, que aborda em suas } \\
\text { composições a maneira de falar do caatingueiro, por outro lado, } \\
\text { Ocorreu (e ainda ocorre) uma forte influência dos meios de } \\
\text { comunicação, principalmente da era do rádio (hoje, através de outros } \\
\text { meios digitais e virtuais), quando o domínio da linguagem era bem } \\
\text { maior da rádio globo, e não de rádio da capital Salvador, mais próxima } \\
\text { geograficamente." }\end{array}$ \\
\hline A.I.R.M & $\begin{array}{l}\text { "Os falantes de Vitória da Conquista apresentam, no uso da língua, } \\
\text { certa similaridade com o falar do norte de Minas Gerais, o que os } \\
\text { distingue bastante dos falantes das demais regiões do estado da Bahia. } \\
\text { Algumas características são apresentadas. Por exemplo: } \\
\text { - um ô antes do vocativo - Ex: Ô Maria, venha cá! } \\
\text { - o plural não é "chiado" } \\
\text { - uma ditongação é criada em certos vocábulos - [nois, rapaiz, } \\
\text { vocêis etc...]" }\end{array}$ \\
\hline
\end{tabular}

Fonte: Rocha (2017, p. 156-157) 
Levando em consideração o Quadro 3, observamos que há quem não observe traços distintivos no modo de falar dos conquistenses, como é o caso dos informantes D.T.B. e I.U.S.S., apesar de este ressaltar que reconhece a diferença dialetal quando em contato com pessoas de outras comunidades linguísticas. Além disso, destacamos que aqueles informantes que consideraram os traços linguísticos que diferenciam o modo de falar dos conquistenses dos falantes de outras localidades do próprio Nordeste, como é o caso de F.S.L.B. e A.L.P, os quais salientam questões de natureza fonética.

Muitos informantes contrastaram a maneira dos conquistenses falar com das pessoas da região metropolitana de Salvador, levando em conta, para tanto, questões lexicais e, sobretudo, fonéticas, como foi o caso dos informantes I.U.S.S., T.M.L.C., C.B.S, M.T.R., V.M.S.N. e A.L.P. Outro aspecto é o fato de alguns informantes sinalizarem uma certa influência de São Paulo na maneira como os conquistenses falam, conforme apontaram F.S.L.B. e E.G.S., este, sobretudo, no momento em que ressalta a influência midiática da Região Sudeste brasileira (especialmente, a Rádio Globo, que surge no Estado de São Paulo). E, sobre tal influência da Região Sudeste do Brasil, constatamos que cerca de $70 \%$ dos informantes que responderam ao teste de avaliação destacaram a forte influência do Estado de Minas Gerais no dialeto conquistense. Algo que, inclusive, discorremos a respeito na subseção 3.1 deste artigo.

Notamos ainda que, ao se particularizar o objeto, investigando gramáticas e estudos linguísticos realizados no Brasil, é possível se observar que alguns autores, a exemplo de Vitral (1996), debatem sobre determinadas restrições sintáticas da variante cê quando comparada com o pronome você. Baseando-se, portanto, nessa premissa, por meio da segunda questão, propomos algumas sentenças e perguntamos qual(is) delas os informantes não diriam. O nosso objetivo, nesse caso, foi o de investigar a percepção dos informantes com relação a tal restrição proposta por Vitral (1996), especialmente, em casos em que o pronome você e cê encontram-se na posição de sujeito e complemento. No Quadro 4, apresentamos os resultados dessa investigação.

Quadro 4 - Avaliação dos informantes com relação a algumas sentenças propostas

\begin{tabular}{|c|c|c|c|c|c|c|c|c|}
\hline \multirow[b]{2}{*}{$\begin{array}{l}\text { INFO } \\
\quad \text { R. }\end{array}$} & \multicolumn{8}{|c|}{ SENTENÇAS AVALIADAS } \\
\hline & $\begin{array}{c}\text { Você pode me } \\
\text { encontrar amanhã. }\end{array}$ & $\begin{array}{c}C \hat{e} \\
\text { passa } \\
\text { lá em } \\
\text { casa. }\end{array}$ & $\begin{array}{c}\text { Você } \\
\text { estuda } \\
\text { onde? }\end{array}$ & $\begin{array}{c}\text { Eu } \\
\text { trouxe } \\
\text { isso } \\
\text { pra } \\
\text { você. }\end{array}$ & $\begin{array}{c}\text { Ele } \\
\text { não } \\
\text { gosta } \\
\text { de } \\
\text { cê. }\end{array}$ & $\begin{array}{l}\text { Cê tá } \\
\text { onde? }\end{array}$ & $\begin{array}{c}\text { Você } \\
\text { pode } \\
\text { pegar } \\
\text { o } \\
\text { ônibus } \\
\text { UESB. }\end{array}$ & $\begin{array}{c}C \hat{e} \\
\text { compra } \\
\text { isso na } \\
\text { farmácia. }\end{array}$ \\
\hline D.T.B. & & & & & $\mathrm{X}$ & & & \\
\hline F.S.L.B & & & & & $\mathbf{X}$ & & & \\
\hline I.U.S.S. & & & & & $\mathbf{X}$ & & & \\
\hline $\begin{array}{l}\text { T.M.L. } \\
\text { C. }\end{array}$ & & & & & $\mathbf{X}$ & & & \\
\hline Y.C. & & & & & $\mathbf{X}$ & & & \\
\hline C.B.S. & & & & & $\mathbf{X}$ & & & \\
\hline G.G.J. & & & & & $\mathbf{X}$ & & & \\
\hline M.T.R. & & & & & $\mathrm{X}$ & & & \\
\hline
\end{tabular}




\begin{tabular}{|c|c|c|c|c|c|c|c|c|}
\hline $\begin{array}{c}\text { V.M.S. } \\
\text { N. }\end{array}$ & & & & X & & & \\
\hline A.L.P. & & & & & X & & & \\
\hline $\begin{array}{c}\text { K.R.L. } \\
\text { A. }\end{array}$ & & & & & $\mathbf{X}$ & & & \\
\hline L.S.S. & & & & & $\mathbf{X}$ & & & \\
\hline N.L.A. & & $\mathbf{X}$ & & & $\mathbf{X}$ & $\mathbf{X}$ & $\mathbf{X}$ & $\mathbf{X}$ \\
\hline A.C. & & & & $\mathbf{X}$ & & & \\
\hline $\begin{array}{c}\text { P.A.R. } \\
\text { C. }\end{array}$ & & & & & $\mathbf{X}$ & & & \\
\hline E.G.S. & & & & $\mathbf{X}$ & & $\mathbf{X}$ & \\
\hline $\begin{array}{c}\text { A.I.R. } \\
\text { M }\end{array}$ & & & & & & & & \\
\hline
\end{tabular}

Fonte: Rocha (2017, p. 159-160)

Avaliamos como interessante os resultados obtidos da questão apresentada no Quadro 4 e chamamos a atenção para uma sentença (Ele gosta de cê.), ressaltando que tal sentença foi categoricamente rejeitada pelos informantes. Esse resultado é um elemento favorecedor à hipótese de que a variante cê não é empregada em posição de objeto sintático, como postula Vitral (1996), afinal, diante das respostas, o uso do pronome cê na posição de complemento, em Vitória da Conquista - BA, não é (tão) aceito. Além dessa sentença, observamos também que dois informantes, K.R.L.A. e A.C., assinalaram as outras sentenças que continham o pronome cie.

Salientamos, ainda, que dois informantes, A.I.R.M. e A.C., destacaram a sentença Você pode pegar o ônibus UESB., como um enunciado que não usariam, porém seus argumentos, referem-se a uma questão, especialmente, de preposição e não, necessariamente, sobre o objeto em si, como pode ser conferido no Quadro 5. Entretanto, frisamos que, apesar dos informantes A.C. e A.I.R.M. avaliarem negativamente a referida sentença, acreditamos que não seja um enunciado incomum no vernáculo conquistense e justificamos tal posicionamento, em função de cerca de $88 \%$ dos informantes que responderam o teste de avaliação não se opuseram ao uso dessa sentença, o que faz com que a atitude linguística dos dois informantes pareça mais uma questão relacionada ao idioleto de ambos.

Logo abaixo das alternativas, foi solicitado aos informantes que justificassem aquelas que fossem rejeitadas por eles. Confiramos, portanto, no Quadro 5, as respostas que foram dadas diante da referida solicitação.

Quadro 5 - Justificativa dada pelos informantes com relação às sentenças que eles sinalizaram que não usariam

\begin{tabular}{|c|l|}
\hline INFORMANTE & \multicolumn{1}{c|}{ JUSTIFICATIVAS } \\
\hline D.T.B. & Ele não gosta de cề "A sua esquisitice. A frase não soa natural." \\
\hline F.S.L.B. & $\begin{array}{l}\text { Ele não gosta de cê: "O motivo que me levou a marcar a alternativa 5 foi o } \\
\text { uso do pronome cê como objeto." }\end{array}$ \\
\hline I.U.S.S. & $\begin{array}{l}\text { Ele não gosta de cế: "É algo distante da minha maneira de falar, utilizar o cê } \\
\text { no final das frases. Portanto, me causa estranheza a sentença." }\end{array}$ \\
\hline T.M.L.C. & $\begin{array}{l}\text { Ele não gosta de cê: "Dentre as alternativas, esta representa a sentença que } \\
\text { certamente nunca utilizei e dificilmente usaria numa conversa espontânea." }\end{array}$ \\
\hline
\end{tabular}




\begin{tabular}{|c|c|}
\hline Y.C. & Ele não gosta de cế: "Porque diríamos 'ela não gosta de você'." \\
\hline C.B.S. & $\begin{array}{l}\text { Ele não gosta de cê: "Marquei a 5, pois me soou estranha, não utilizo o 'cê' em } \\
\text { final de frase a não ser em junções com a preposição 'para' (procê)." }\end{array}$ \\
\hline G.G.J. & $\begin{array}{l}\text { Ele não gosta de cê: "Uso frequentemente o Cê, mas nessa situação em } \\
\text { especial não usaria, acho que faltou concordância." }\end{array}$ \\
\hline M.T.R. & Ele não gosta de cê: "Não gostei da frase quando a pronunciei." \\
\hline V.M.S.N. & $\begin{array}{l}\text { Ele não gosta de cê: "Utilizo o pronome CÊ com certa frequência, mas apenas } \\
\text { verbalmente e no início das frases." }\end{array}$ \\
\hline A.L.P. & $\begin{array}{l}\text { Ele não gosta de cê: "Esse especificamente, em minha opinião, fica feio a } \\
\text { sonoridade do uso do pronome Cê. O você fica mais coeso e mais harmônico." }\end{array}$ \\
\hline K.R.L.A. & $\begin{array}{l}\text { Ele não gosta de cê. / Cê passa lá em casa. / Cê compra isso na farmácia. } \\
\text { : "Não costumo usar "cê', mas as vezes uso o TU substituído o você." }\end{array}$ \\
\hline L.S.S. & $\begin{array}{l}\text { Ele não gosta de cê: "Nunca me imaginei usando essa expressão ou falando } \\
\text { assim e algum contexto. Achei feio." }\end{array}$ \\
\hline N.L.A. & $\begin{array}{l}\text { Ele não gosta de cế: "Não costumo usar o Cê, além de nessa frase especifica a } \\
\text { fonética dar outro sentido na frase." }\end{array}$ \\
\hline A.C. & $\begin{array}{l}\text { Ele não gosta de cê. / Cê passa lá em casa. / Cê compra isso na farmácia. } \\
\text { / Cê tá onde? : "Não costumo usar o pronome de tratamento "Cê", embora } \\
\text { conheça algumas pessoas que o faça." } \\
\text { Você pode pegar o ônibus UESB: "Na alternativa do ônibus diria: Você pode } \\
\text { pegar o ônibus que leva até a UESB, ou que passa pela UESB. Não conheço } \\
\text { pessoas que usem a expressão cujo intinerário seja o nome do ônibus." }\end{array}$ \\
\hline P.A.R.C. & $\begin{array}{l}\text { Ele não gosta de cế: "A forma abreviada de se pronunciar 'você' ('cê') é } \\
\text { relativamente comum entre os conquistenses, mas apenas para iniciar uma frase, } \\
\text { jamais citando-a no seu final. }\end{array}$ \\
\hline E.G.S. & $\begin{array}{l}\text { Ele não gosta de cê: "A frase pode estar certa, mas não costumo falar dessa } \\
\text { maneira. Diria: Ele não gosta de você." }\end{array}$ \\
\hline A.I.R.M & $\begin{array}{l}\text { Ele não gosta de cê: "Em Vitória da Conquista, CÊ é um pronome de } \\
\text { tratamento, mas que só é usado quando ele é sujeito da oração.Tal fato sintático } \\
\text { o diferencia do pronome VOCÊ, vez que usamos 'Ele não gosta de VOCÊ'." } \\
\text { Você pode pegar o ônibus UESB: "Sem a preposição DE, não costumamos } \\
\text { usar tal frase." }\end{array}$ \\
\hline
\end{tabular}

Fonte: Rocha (2017, p. 160-161)

Em relação à sentença Ele gosta de cê., todos os informantes categórica e consensualmente rejeitaram-na. Para tanto, foram apresentados argumentos ora mais detalhados ora mais sintéticos. A exemplo disso, notamos que alguns informantes, como D.T.B e L.S.S., resumem-se a qualificadores de natureza negativa para justificar sua rejeição face à referida construção. Porém, outros informantes, como F.S.L.B., C.B.S., V.M.S.N. e P.A.R.C., justificam sua atitude linguística em função da posição na qual o pronome cê foi empregado na sentença. Já alguns informantes rejeitaram a referida sentença em função da sua sonoridade, que, para eles, causava-lhes estranhamento, como foi o caso dos informantes M.T.R., A.L.P. e N.L.A. E houve aqueles, ainda, como Y.C., A.L.P e E.G.S., que sugeriram a troca pronominal do cê.

É salutar percebermos que C.B.S. fala do uso pronominal preposicionado, quando afirma que: “[...]não utilizo o 'cê' em final de frase a não ser em junções com a preposição "para' (procê)" (Cf. Quadro 5). Porém, apesar da ressalva feita, a informante "inconscientemente" emprega a forma pronominal ocê, ao invés de cê, na proposição que faz. Segundo Vitral (1996), a forma ocê assume as posições sintáticas previstas para o 
pronome você, o que justificaria o uso proposto pela informante, apesar de ela pensar estar empregando a forma sincopada cê numa construção preposicionada.

Ainda sobre o Quadro 5, notamos que dois informantes, K.R.L.A e A.C., assinalaram as outras sentenças que continham o pronome $c \hat{e}$, todavia, suas justificativas nos chamaram atenção, pois, segundo os informantes, eles não fazem o uso da forma sincopada em análise. A informante K.R.L.A., inclusive, salientou que, ao invés de permutar o pronome você pela sua forma variante cê, ela, às vezes, emprega a forma $t u$.

Cabe ainda observar que os informantes A.C. e A.I.R.M., ambos da faixa III, referiram-se ao pronome cê como um pronome de tratamento. Porém, a forma sincopada $c \hat{e}$, assim como o pronome você, apesar de terem surgido na língua como uma forma de tratamento, na atualidade, funcionam produtivamente, no vernáculo conquistense, como pronomes pessoais do caso reto.

A seguir, apresentamos o Quadro 6, no qual mostramos as respostas para a terceira questão, a qual foi feita com vistas a investigar a percepção/avaliação dos informantes a respeito da alternância pronominal entre o você e o cê na comunidade de Vitória da Conquista - BA. Vejamos:

Quadro 6 - As respostas do teste de avaliação para a terceira pergunta sobre a alternância pronominal entre o você e o $\hat{e}$

\begin{tabular}{|c|c|}
\hline \multicolumn{2}{|c|}{$\begin{array}{l}\text { PERGUNTA: Estudos comprovam que os conquistenses usam tanto o pronome VOCÊ quanto } \\
\text { o pronome CE. Você também usa os dois pronomes? Por favor, apresente uma breve } \\
\text { justificativa. }\end{array}$} \\
\hline INFORMANTE & RESPOSTAS \\
\hline D.T.B. & $\begin{array}{l}\text { "Sim. Mesmo reconhecendo o uso recorrente do pronome "tu", as formas 'cê' e } \\
\text { 'você' também são muito usadas. Ambas aparecendo em contextos formais e } \\
\text { informais, diferentemente do 'tu', que fica adstrito à informalidade, ao que me } \\
\text { parece." }\end{array}$ \\
\hline F.S.L.B. & $\begin{array}{l}\text { "Sim, eu uso os dois pronomes. A fala coloquial permite que eu escolha qual } \\
\text { pronome usar. Em contextos mais informais cabe usar o cê."" }\end{array}$ \\
\hline I.U.S.S. & $\begin{array}{l}\text { "Sim, como respondido na questão anterior, acho estranho a utilização do } \\
\text { pronome CÊ no final das frases. Porém, no início das sentenças é um tanto } \\
\text { quanto normal sua utilização. Como na situação "CÊ comprou isso na farmácia?" }\end{array}$ \\
\hline T.M.L.C. & $\begin{array}{l}\text { "Sim. O uso do CE normalmente ocorre em diálogos que não exigem } \\
\text { formalidade." }\end{array}$ \\
\hline Y.C. & $\begin{array}{l}\text { "Sim, por exemplo as alternativas anteriores, 'cê tá onde', 'cê tá fazendo o que?'... } \\
\text { Entretanto esses pronomes só são usados na fala, apesar de que quem pronuncia } \\
\text { na maioria das vezes escreve de outra forma, ou seja, fala de um jeito "errado", } \\
\text { mas escrevem certo." }\end{array}$ \\
\hline C.B.S. & $\begin{array}{l}\text { "Sim, creio que faço uma alternância entre os dois. Noto que utilizo o 'cê' } \\
\text { principalmente em situações corriqueiras, quando não faço um policiamento da } \\
\text { fala, comportamento típico de situações informais. }\end{array}$ \\
\hline G.G.J. & $\begin{array}{l}\text { "Uso frequentemente, e isso, herdei da convivência com minha avó e de até } \\
\text { mesmo dos colegas do primário, pois é muito comum abreviar algumas palavras." }\end{array}$ \\
\hline M.T.R. & $\begin{array}{l}\text { "Sim, uso os dois pronomes. O pronome VOCÊ é o que eu mais uso, } \\
\text { principalmente na escrita. Porém, sempre uso o CÊ na fala." }\end{array}$ \\
\hline V.M.S.N. & $\begin{array}{l}\text { "Utilizo regularmente os dois pronomes. Todavia, opto pelo uso do } \mathrm{CE} \text { apenas } \\
\text { em linguagem coloquial com pessoas mais próximas, como familiares e amigos } \\
\text { íntimos. Em relação ao VOCE utilizo com mais frequência e principalmente em }\end{array}$ \\
\hline
\end{tabular}




\begin{tabular}{|c|c|}
\hline & $\begin{array}{l}\text { diálogos mais formais, com colegas de trabalho, autoridades e pessoas } \\
\text { desconhecidas, por exemplo." }\end{array}$ \\
\hline A.L.P. & $\begin{array}{l}\text { "Por mais que sabemos que a forma correta é você, acabo utilizando o cê quase } \\
\text { que de forma automática em vários momentos, principalmente nos diálogos com } \\
\text { pessoas mais próximas." }\end{array}$ \\
\hline K.R.L.A. & "Uso o você, mas é muito comum o uso do cê em diálogos que participo." \\
\hline L.S.S. & $\begin{array}{l}\text { "Uso em bate papo entre amigos, e como uma expressão de exagerada alegria 'Cê } \\
\text { tá doido'." }\end{array}$ \\
\hline N.L.A. & $\begin{array}{l}\text { "Normalmente uso o você, no entanto, em conversas informais ocasionalmente } \\
\text { posso utilizar esse pronome cê." }\end{array}$ \\
\hline A.C. & "Não uso embora identifique quem o faça, mas sem muita frequência." \\
\hline P.A.R.C. & $\begin{array}{l}\text { "Sim, eu posso usar as duas formas. Costumo usar 'cê' na linguagem falada. } \\
\text { Abreviações facilitam e tornam mais ágil a fala. Na linguagem escrita, sempre } \\
\text { utilizo apenas 'vocề', porque nessa forma de expressão há mais tempo para pensar } \\
\text { e se manifestar com expressões que me parecem mais corretas." }\end{array}$ \\
\hline E.G.S. & $\begin{array}{l}\text { "O pronome você a gente costuma usar de forma mais formal, quanto a Cê, } \\
\text { utiliza-se de maneira mais descontraída em bate-papo, barzinho, etc. na } \\
\text { informalidade, linguagem popular, coloquial." }\end{array}$ \\
\hline A.I.R.M & $\begin{array}{l}\text { "Sim, confirmo: os dois usos são intercambiáveis, na maioria das situações } \\
\text { linguísticas." }\end{array}$ \\
\hline
\end{tabular}

Fonte: Rocha (2017, p. 162-163)

A partir do Quadro 6, destacamos que há um consenso entre os informantes no que tange à variação dos pronomes você e cên na comunidade de Vitória da Conquista. Todos reconheceram que os conquistenses usam tanto o pronome você quanto a sua forma variante $c \hat{e}$, todavia, dois dos informantes, K.R.L.A. e A.C., apesar de tal reconhecimento, asseguraram que não usam a forma sincopada cê. Dentre as colocações, salientamos a avaliação do informante D.T.B, o qual retoma a ocorrência do pronome tu no vernáculo em estudo, considerando o uso dessa forma pronominal restrito a contextos de informalidade.

É necessário, também, destacar que a alternância de formalidade foi uma questão recorrentemente abordada entre as respostas dos informantes. Quando mencionado o tópico formalidade, eles alinharam o uso do você a contextos caracterizados pela formalidade, ao passo que o uso do pronome cê estaria relacionado aos contextos nos quais impera a informalidade. Cabe acentuarmos, ainda, que três informantes, Y.C., M.T.R. e P.A.R.C., diferenciaram o uso pronominal a partir da modalidade do texto, isto é, em textos escritos, a preferência de uso recairia sobre o pronome você, enquanto, na oralidade, haveria o favorecimento do uso da forma sincopada $c \hat{e}$. Relacionando, dessa forma, a modalidade oral ao uso informal, caracterizada pela forma $c \hat{e}$ e a modalidade escrita, por sua vez, ao uso formal, caracterizado, nesse contexto, pelo uso da forma você.

Chamamos atenção para as respostas de dois informantes, Y.C. e A.L.P., na medida em que as concepções de certo e errado foram retomadas. Para ambos, há uma ideia de que o você assume o lugar da forma certa, ao passo que o cê é considerado uma forma errada. Y.C., por sua vez, tenta até modalizar o uso do qualificador errado por meio das aspas. As colocações desses dois informantes fomentam a reflexão sobre o papel da escola, afinal, é, no contexto escolar, que há a normativização da língua e onde concepções como essas são comumente reproduzidas mediante as prescrições encontradas nos 
materiais didáticos. É pertinente, também, ressaltar a importância do uso de materiais didáticos que lancem mão de dados linguísticos reais, uma vez que, por meio desse caminho, é possível desmistificar a ideia de certo e errado e, consequentemente, dar lugar à compreensão da adequabilidade nos diferentes contextos linguísticos.

Destacamos, ainda, a colocação da informante V.M.S.N., pois, além de ela tratar da questão da formalidade, a informante diferencia o uso do pronome você e cê de acordo com o grau de intimidade que possui com o seu interlocutor. Para ela, quando a situação linguística requer dado distanciamento interpessoal, a forma empregada será o pronome vocé; por outro lado, com interlocutores próximos, como familiares e amigos íntimos, sua preferência de uso pronominal recai sobre a forma sincopada cê. A resposta dessa informante remete à maneira como os informantes A.C. e A.I.R.M referiram-se à forma sincopada $c \hat{e}$, quando a denominaram de pronome de tratamento.

Outra resposta relevante para a pesquisa foi a da informante A.I.R.M., em que, segundo a respondente, tanto o pronome você quanto a sua forma variante cế, na maioria dos contextos linguísticos, são intercambiáveis. Já a informante G.G.J., por seu turno, reconhece que emprega as duas formas e argumenta ter herdado tal atitude linguística de sua avó e de seus colegas do fundamental I. Enquanto que a informante L.S.S. faz uma consideração bastante interessante sobre o pronome cê. De acordo com ela, o referido pronome é empregado em sua fala quando usa a expressão 'Cề tá doido?', o que nos leva a alinhar tal expressão àquelas que já se encontram cristalizadas na língua e que, por vezes, já sofreram mudanças estruturais em função da frequência de uso.

$\mathrm{Na}$ sequência, a partir do Quadro 7, exibimos as respostas dadas para a quarta pergunta, por meio da qual buscamos, mais diretamente, a nosso ver, investigar a avaliação dos informantes, especificamente, quanto à forma pronominal che, uma vez que os resultados da amostra investigada sinalizavam para um aparente estigma quanto a essa variante.

Quadro 7 - As respostas do teste de avaliação para a quarta pergunta sobre a percepção/avaliação do uso do pronome $c \hat{e}$

\begin{tabular}{|l|l|}
\hline \multicolumn{2}{|l|}{ PERGUNTA: $\boldsymbol{O}$ que você acha do uso do pronome $\boldsymbol{C} \hat{E} ?$} \\
\hline INFORMANTE & RESPOSTAS \\
\hline D.T.B. & "Dotado de sonoridade agradável." \\
\hline F.S.L.B. & $\begin{array}{l}\text { "Eu não tenho uma opinião quanto ao uso do cê ser positivo ou negativo. Da } \\
\text { maneira como eu vejo, é simplesmente inevitável. As línguas humanas mudam." }\end{array}$ \\
\hline I.U.S.S. & $\begin{array}{l}\text { "Penso ser uma maneira de abreviarmos as sentenças, utilizando esse pronome } \\
\text { para agilizarmos nossa fala. Hoje é algo tão comum de ser falado, que nem nos } \\
\text { apercebemos de sua utilização, assim como a utilização do 'vc' nos meios } \\
\text { tecnológicos." }\end{array}$ \\
\hline T.M.L.C. & $\begin{array}{l}\text { "Acredito que torna a conversa mais informal, utilizado normalmente com } \\
\text { pessoas mais próximas. Entretanto, isso não ocorre de maneira premeditada." }\end{array}$ \\
\hline Y.C. & $\begin{array}{l}\text { "Econômico, não na escrita, mas na fala, a informação é passada de forma que o } \\
\text { receptor consegue entender em um curto espaço de tempo." }\end{array}$ \\
\hline C.B.S. & "Gosto de utilizá-lo. É simples, prático e tem a mesma eficiência que o 'você’."' \\
\hline G.G.J. & "Não apropriado, mas no meu caso se tornou um vício de linguagem."” \\
\hline M.T.R. & $\begin{array}{l}\text { "Acho bastante interessante para ser usado na fala, principalmente em conversas } \\
\text { informais." }\end{array}$ \\
\hline
\end{tabular}




\begin{tabular}{|c|c|}
\hline V.M.S.N. & $\begin{array}{l}\text { "Creio que seja parte da evolução da língua portuguesa haja vista que o pronome } \\
\text { VOCÊ teve origem como expressão de tratamento (vossa mercê), passando por } \\
\text { vosmecê, que caiu em desuso, sendo substituído por VOCÊ, OCÊ e CÊ." }\end{array}$ \\
\hline A.L.P. & $\begin{array}{l}\text { "Eu prefiro o Você, acho que fazemos uso do Cê mais como forma de } \\
\text { abreviação, ou também pela constante convivência com pessoas que o utilizam } \\
\text { muito." }\end{array}$ \\
\hline K.R.L.A. & $\begin{array}{l}\text { "Penso que pode ser influência do jeito de falar mineiro, que costuma diminuir } \\
\text { sílabas e fonemas na língua falada. Na oralidade não vejo problemas, já faz até } \\
\text { parte do vocabulário popular, é um jeito carinhoso e produz a ideia de } \\
\text { intimidade." }\end{array}$ \\
\hline L.S.S. & $\begin{array}{l}\text { "Sem a preocupação de onde estamos e de quem está nos ouvindo o CÊ faz a } \\
\text { conversa, mas intimista e menos polida, com orações mas breves." }\end{array}$ \\
\hline N.L.A. & "Acho meio antigo, lembro bastante de pessoas mais idosas." \\
\hline A.C. & $\begin{array}{l}\text { "Considero uma violência fonética, mas reconheço que é mais usado por pessoas } \\
\text { que não passaram pelo benefício de uma educação formal." }\end{array}$ \\
\hline P.A.R.C. & "Uma maneira menos formal (e ágil) de se dirigir a uma outra pessoa." \\
\hline E.G.S. & $\begin{array}{l}\text { "A língua portuguesa é muita rica, muitas vezes alguns diminutivos podem criar } \\
\text { códigos de entendimentos de um determinado grupo ou comunidade. É salutar." }\end{array}$ \\
\hline A.I.R.M & $\begin{array}{l}\text { "CÊ é uma segunda redução do pronome VOCÊ. (VOCÊ - OCÊ - CÊ) } \\
\text { Entretanto vale ressaltar que o pronome VOCÉ já é a quarta redução de VOSSA } \\
\text { MERCÊ (VOSSA MERCE - VOSMICE - VANSUNCE - VOCE - OCE - } \\
\text { CÊ" }\end{array}$ \\
\hline
\end{tabular}

Fonte: Rocha (2017, p. 165-166)

Com o Quadro 7, concentramo-nos no pronome cê e sinalizamos a confirmação da hipótese de que tal forma pronominal não sofre estigma na comunidade de Vitória da Conquista - BA. Quatro informantes avaliaram positivamente a variante $c \hat{e}$, como, por exemplo: (i) o informante D.T.B. considerou que o referido pronome é dotado de sonoridade agradável; (ii) a informante M.T.R. avaliou-o como bastante interessante para a oralidade e em contextos informais; (iii) K.R.L.A., apesar de, em outras momentos do teste, assumir que não usa o pronome $c \hat{e}$, afirmou que é um a forma pronominal que promove uma ideia de carinho e intimidade; e (iv) o informante E.G.S. considerou o pronome $c \hat{e}$ como salutar.

Outros aspectos do pronome cê apontados pelos informantes foram sua economia e praticidade, como sinalizaram, por exemplo, os informantes I.U.S.S, Y.C., C.B.S. e P.A.R.C. Alguns deles associaram tal economia e praticidade à redução estrutural da forma sincopada cê. Tratando-se também disso, duas informantes, V.M.S.N. e A.I.R.M., levaram em consideração a origem do $c \hat{e}$, retomando os estágios primários da forma pronominal, quando ainda funcionava na língua como a forma de tratamento Vossa Mercê. E a informante N.L.A., por sua vez, avaliou o pronome cê como uma forma antiga, o que a remetia, inclusive, às pessoas idosas. Essa avaliação faz-nos retomar as considerações da informante G.G.J. para a terceira pergunta do teste de avaliação, quando assinalou que sofreu influência da avó.

Avaliamos, ainda, como muito interessante o que I.U.S.S. e T.M.L.C. apontam quanto ao uso do pronome cê. Segundo ambos, o uso desse pronome não acontece conscientemente. I.U.S.S., por exemplo, argumenta que “[...] Hoje é algo tão comum de ser falado, que nem nos apercebemos de sua utilização [...]”. Já T.M.L.C., por seu turno, 
argumenta que o uso do cê em seus contextos linguísticos "[...] não ocorre de maneira premeditada".

Não poderíamos deixar de comentar a avaliação negativa que foi feita pelo informante A.C., considerando o pronome cê como uma "violência fonética", além de alegar que o seu uso decorre da falta de escolarização. Argumenta, por outro lado, que, ao longo das discussões, paulatinamente, é possível nos darmos por convencidos de que o pronome cê não sofre estigma na comunidade Vitória da Conquista - BA, reforçando a hipótese de que a avaliação desse informante é algo peculiar ou isolado (Cf. Quadro 5). Além disso, na primeira etapa da pesquisa, constatamos que foram os informantes escolarizados da faixa III que favoreceram o uso da variante $c \hat{e}$, a faixa etária que se encontra, inclusive, o referido informante.

Em vias de conclusão dessa seção, no Quadro 8, apresentamos as respostas dadas à última questão do teste de avaliação, por meio da qual procuramos investigar o papel do pronome tu no vernáculo conquistense, posto que foram encontrados $5 \%$ do valor total de ocorrências de referência à segunda pessoa nos corpora analisados, além das considerações feitas por alguns informantes nas primeiras perguntas do teste de avaliação.

Quadro 8 - As respostas do teste de avaliação para a quinta pergunta sobre a percepção do informantes com relação ao seu comportamento linguístico no que tange ao uso, ou não, do pronome $t u$ e, em casos afirmativos, em quais contextos linguísticos

\begin{tabular}{|c|c|}
\hline \multicolumn{2}{|c|}{$\begin{array}{l}\text { PERGUNTA: Você usa o pronome TU? Em que situaçôes você usa (ou prefere usar) o tu em } \\
\text { detrimento ao VOCÊ/CÊ? }\end{array}$} \\
\hline INFORMANTE & RESPOSTAS \\
\hline D.T.B. & $\begin{array}{l}\text { "Uso o pronome 'tu' com frequência, especialmente em contextos relações } \\
\text { sociais mais íntimas, como nos círculos de familiares e amigos." }\end{array}$ \\
\hline F.S.L.B. & $\begin{array}{l}\text { "Eu já me peguei usando o pronome tu, mas não sei especificar em que situações } \\
\text { eu faço uso desse pronome." }\end{array}$ \\
\hline I.U.S.S. & $\begin{array}{l}\text { "Utilizo muito raramente, sendo até difícil determinar um momento que prefiro } \\
\text { a utilização do TU em detrimento ao VOCÊ. A utilização preponderante ainda } \\
\text { continua sendo o VOCÊ/CÊ." }\end{array}$ \\
\hline T.M.L.C. & $\begin{array}{l}\text { "Normalmente não utilizo o pronome TU. Acredito que apenas o utilizo ao } \\
\text { estudar assuntos gramaticais que necessariamente necessitam de sua utilização, } \\
\text { como na conjugação verbal." }\end{array}$ \\
\hline Y.C. & "São raras as vezes, por exemplo, 'por tua causa' ao invés de 'por causa de você'." \\
\hline C.B.S. & $\begin{array}{l}\text { "Sim, mas não conjugo o verbo conforme a gramática normativa. Eu uso o 'tu' } \\
\text { principalmente quando me irrito com a atitude de alguém e repreendo essa } \\
\text { pessoa através da fala. Nesse contexto, utilizo frases como 'moss, tu tá doido, } \\
\text { é?"” }\end{array}$ \\
\hline G.G.J. & "Geralmente uso em questionamentos." \\
\hline M.T.R. & $\begin{array}{l}\text { "Sim, uso o pronome TU. Prefiro usá-lo em conversas com amigos mais } \\
\text { próximos. Principalmente quando preciso aconselhar alguém." }\end{array}$ \\
\hline V.M.S.N. & $\begin{array}{l}\text { "Não utilizo o pronome TU. Creio que por uma questão de regionalismo já que } \\
\text { as pessoas de Vitória da Conquista comumente não utilizam esse pronome na } \\
\text { linguagem coloquial." }\end{array}$ \\
\hline A.L.P. & $\begin{array}{l}\text { "Uso, apesar de preferir você, mas assim como o Cê, creio eu, que uso mais nos } \\
\text { diálogos com pessoas mais próximas, a exemplo da família em casa, de conversas } \\
\text { com amigos. Sempre que posso, que percebo antes de falar que iria utilizar o Tu, } \\
\text { substituo-o por Você." }\end{array}$ \\
\hline
\end{tabular}




\begin{tabular}{|l|l|}
\hline K.R.L.A. & $\begin{array}{l}\text { "Uso bastante em situações informais e o pior de tudo é que substituo o você } \\
\text { pelo tu sem conjugar devidamente o verbo." }\end{array}$ \\
\hline L.S.S. & $\begin{array}{l}\text { "Muitas vezes quando faço uma pergunta e que desejo que a outra pessoa } \\
\text { perceba a minha urgência e um tom de solicitação. Com pessoa muito intima." }\end{array}$ \\
\hline N.L.A. & $\begin{array}{l}\text { "Dificilmente. Quando uso em detrimento a você." } \\
\text { "O uso da segunda pessoa não é muito comum em Conquista, geralmente é } \\
\text { usado numa linguagem mais formal." }\end{array}$ \\
\hline P.A.R.C. & $\begin{array}{l}\text { "Tu' é um pronome que não faz parte do meu vocabulário, nem mesmo na } \\
\text { linguagem escrita." }\end{array}$ \\
\hline E.G.S. & $\begin{array}{l}\text { "A verdade é que em nossa região utiliza-se muito pouco o pronome TU. O } \\
\text { pronome você é utilizado comumente." }\end{array}$ \\
\hline A.I.R.M & $\begin{array}{l}\text { "O falante de Vitória da Conquista usa muito pouco o TU, e quando usa é com } \\
\text { o verbo de terceira pessoa. Ex.: TU quer doce? } \\
\text { Eu, particularmente, por questão de estilo, às vezes, uso o TU, porém com a } \\
\text { forma verbal da pessoa 2."” }\end{array}$ \\
\hline
\end{tabular}

Fonte: Rocha (2017, p. 167-168)

A partir do exposto no Quadro 8, observamos que o pronome tu divide opiniões entre os informantes, e, consequentemente, entre os conquistenses. Os informantes A.C. e E.G.S., por exemplo, não responderam se fazem o uso ou não do pronome $t u$, todavia, a partir de suas respostas, depreende-se que não o fazem. Segundo os referidos informantes, o uso desse pronome não é recorrente na fala dos conquistenses e, para A.C., o seu emprego, quando feito, limita-se aos contextos que demandam formalidade. Há, ainda, quem acredite que os falantes de Vitória da Conquista - BA não usam o pronome tu, como é o caso da informante V.M.S.N., alegando ser uma questão de regionalismo cuja aplicação não se observa no locus da presente pesquisa.

Dentre os informantes que admitiram usar o pronome $t u$, I.U.S.S e Y.C. ressaltaram que o fazem raramente. E de acordo com o informante Y.C, o uso do pronome tu revelase na sua fala em casos específicos, como, por exemplo, quando há o emprego do pronome possessivo concordando com a segunda pessoa do singular. Acrescentamos que quatro informantes, C.B.S. G.G.J., M.T.R. e L.S.S., argumentaram que o uso do tu está associado a situações específicas, a saber, quando repreendem, questionam, solicitam ou aconselham.

$\mathrm{Na}$ sequência, destacamos que dois informantes, além de V.M.S.N., também alegaram não usar o pronome $t u$, como foi o caso de P.A.R.C. e T.M.L.C. Este, por seu turno, acrescentou que apenas inclui o referido pronome em sua fala quando está diante de uma situação de estudo formal, em que há a necessidade de se deter aos assuntos gramaticais, como, por exemplo, no momento de conjugar algum verbo.

Alguns informantes associaram o uso do pronome tu às situações em que há dada intimidade com os seus interlocutores, como foi o caso dos informantes D.T.B., A.L.P. e L.S.S. Ressaltamos que, dentre esses informantes, a colocação de A.L.P. é bastante reveladora, visto que, segundo o informante, quando há uma situação de maior monitoramento da sua parte, ele evita usar o pronome tu em detrimento do você, o que nos leva ao questionamento dessa atitude linguística, dando margem, inclusive, a possibilidade de um estudo mais específico futuramente. 
Acentuamos também que, além da questão da proximidade apontada, a informante K.R.L.A., diferentemente de A.C., avalia o uso do pronome tu mais apropriado aos contextos informais, nos quais, inclusive, há o pouco monitoramento da fala, o que justificaria, portanto, a colocação do informante F.S.L.B, quando este afirma já ter se observado utilizando o item como se fosse algo que fugisse do seu controle.

Trazemos, ainda, uma questão relacionada à concordância entre verbo e pronome. Nesse diapasão, destacamos que três informantes, C.B.S., K.R.L.A., A.I.R.M., retomaram esse assunto quando questionadas sobre o emprego do tu, cuja conjugação, de acordo com a prescrição gramatical, deve concordar com a $2^{a}$ pessoa do singular. As informantes C.B.S. e K.R.L.A. afirmaram que, apesar de usar o pronome $t u$, fazem-no sem conjugar o verbo que o acompanha conforme a prescrição gramatical. Todavia, a informante A.I.R.M, por seu turno, assegura que, por uma questão de estilo, quando lança mão do pronome de $2^{\text {a }}$ pessoa, conjuga o verbo também na pessoa do discurso correspondente.

Assim, concluímos, na investigação realizada, que a aplicação do teste de avaliação foi bastante importante para a pesquisa, na medida em que foi possível cruzar os resultados obtidos tanto do estudo da amostra, cuja apresentação neste artigo foi feita na subseção 2.2, quanto do conteúdo extraído do teste de avaliação, ora debatido, observando, assim, evidências suficientes para confirmar a hipótese de que o pronome $c \hat{e}$ não sofre estigma na comunidade de Vitória da Conquista - BA. Ademais, sublinhamos que existem elementos que podem promover a realização de pesquisas futuras, como, por exemplo, a realização direta ou indiretamente do pronome tu na amostra analisada.

A seguir, na próxima seção, apresentamos as nossas últimas ponderações, as quais são seguidas das referências utilizadas até aqui.

\section{CONCLUSÃO}

No presente artigo, apresentamos, sumariamente, na subseção 2.2, a corrente teórico-metodológica que amparou a pesquisa de Rocha (2017), o Sociofuncionalismo, cujo delineamento encontra-se na interseção de duas correntes teóricas, a saber a Sociolinguística Variacionista e o Funcionalismo Norte-Americano voltado ao estudo da gramaticalização. Ressaltamos ainda que, em função do enfoque dado neste texto, alinhamos o debate feito a uma perspectiva sociofuncional mais engajada à Sociolinguística Variacionista.

Demos evidência a três categorias propostas por Labov (2008 [1972]) para análise do significado social das variantes, sendo elas: estereótipos, marcadores e indicadores. Concluímos, diante das informações apresentadas tanto na subseção 2.3 quanto na seção 4, que não se observa, entre as variantes estudadas por Rocha (2017), o indício da presença de estereótipos na comunidade focalizada, salvo o caso isolado, em que o informante A.C. considera que a variante cê consiste em uma "violência fonética" a caracteriza como um traço da fala de pessoas não escolarizadas.

A despeito da avaliação desse informante, podemos afirmar que, no que tange à alternância dos pronomes você e cê na comunidade de Vitória da Conquista, é razoável defender que há a presença, mormente, de marcadores, pois, considerando a primeira 
parte do estudo e, sobretudo, as avaliações dos informantes no teste aplicado a posteriori, observamos que o emprego das duas variantes subjaz a uma variação estilística e social. Em outras palavras, a alternância dos pronomes relaciona-se, na maioria dos casos, com questões de formalidade e intimidade na esfera estilística e, também, corresponde a questões no âmbito social, como faixa etária, sexo e escolaridade.

Todavia, embora assumamos tal posicionamento quanto aos valores sociais das variantes, é importante ressaltarmos que, para alguns informantes, a escolha entre uma ou outra forma pronominal não se dá conscientemente. Isso, portanto, levar-nos-ia a afirmar que estes informantes compreendem o uso como indicador. Não havendo, ainda assim, a presença de estigma que funcionaria como um vetor para acelerar ou desacelerar uma mudança linguística no vernáculo conquistense.

Por fim, concluímos que o presente estudo enriquece o campo das pesquisas voltadas à investigação pronominal no Português Brasileiro, além de se caracterizar como pioneiro sobre a temática à luz do Sociofuncionalismo, na Região do Sertão da Ressaca, e, consequentemente, abrir espaço para outros diálogos no que diz respeito ao objeto focalizado.

\section{REFERÊNCIAS}

GUY, G. R.; ZILLES, A.. Sociolinguística quantitativa - instrumento de análise. São Paulo: Parábola Editorial, 2007.

HEINE, B. Grammaticalization. In: JOSEPH, B. D.; JANDA, R. D. The handbook of historical linguistics. Blackwell handbooks in linguistics. Oxford/Malden, MA: Blackwell Publishing, 2003.

HEINE, B.; CLAUDI, U.; HUNNEMEYER, F. Grammaticalization: a conceptual framework. Chicago: The University of Chicago Press, 1991.

HOPPER, P. J. Emergent grammar. In: BLS. v. 13, p. 139-157, 1987.

HOPPER, P. J. On some principles of grammaticization. In: TRAUGOTT, E. C.; HEINE, Bernd (eds.). Approaches to Grammaticalization. Vol.1: Focus on Theoretical and Methodological Issues. Amsterdam/Philadelphia: John Benjamins. p. 17-35, 1991.

HOPPER, P. J.; TRAUGOTT, E. C. Grammaticalization. 2. ed. Cambridge: Cambridge University Press, 2003.

LABOV, W. Padrões Sociolinguísticos. Trad. de M. Bagno; M. M. P. Scherre; C. R. Cardoso. São Paulo: Parábola Editorial, 2008 [1972].

ROCHA, W. J. C. Você e Cê: um estudo sociofuncional em uma comunidade do Sertão da Ressaca. 2017. Dissertação de Mestrado Acadêmico - UESB, Vitória da Conquista - BA, 2017.

TARAlLO, F. L. A pesquisa sociolingüistica. 8. ed. São Paulo: Ática, 2007. 
TAVARES, M. A. A gramaticalização de E, AÍ, DAÍ e ENTÃO: estratificação/variação e mudança no domínio funcional da sequenciação retroativo-propulsora de informações um estudo sociofuncionalista. Tese de Doutorado em Linguística - UFSC: Florianópolis, 2003.

TAVARES, M. A. Sociofuncionalismo: um duplo olhar sobre a variação e a mudança linguística. Interdisciplinar-Revista de Estudos em Língua e Literatura, v. 17, p. 27-48, 2013. TAVARES, M. A.; GÖRSKI, E. M. Variação e Sociofuncionalismo. In.: MARTINS, M. A.; ABRAÇADO, J (Org). Mapeamento sociolinguístico do português brasileiro. São Paulo: Contexto, 2015.

VITRAL, L. A forma CÊ e a noção de gramaticalização. Revista de Estudos da Linguagem, ano 5, n. 4, v. 1, UFMG, p. 116-124, 1996.

WEINREICH, U.; LABOV, W.; HERZOG, M. I. Fundamentos empíricos para uma teoria da mudança linguística. Trad. de Marcos Bagno. São Paulo: Parábola, 2006[1968].

Recebido em: 28/11/2019

Aprovado em: 07/01/2020

Publicado em: 30/04/2020 